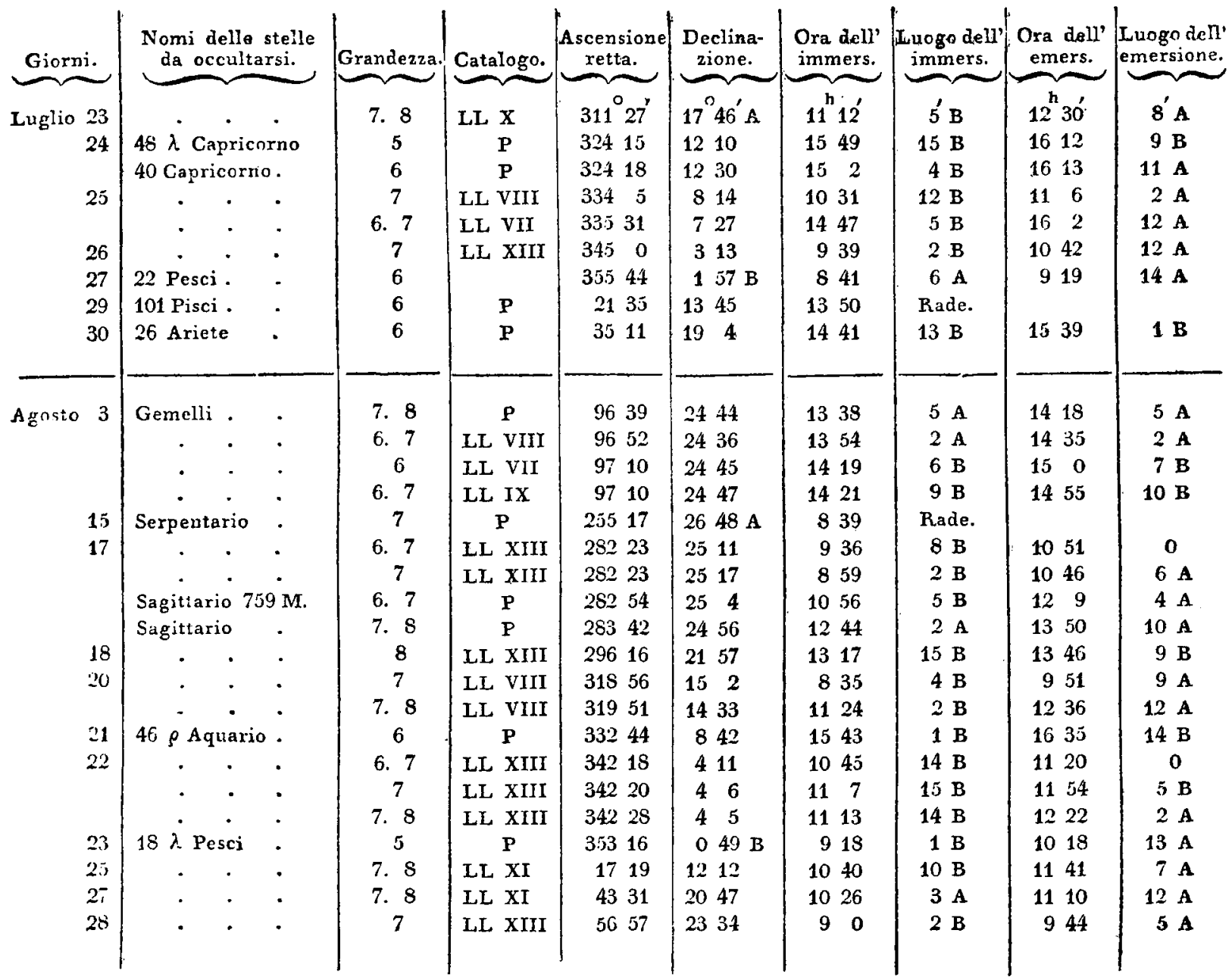

(Der Beschlurs folgt.)

\title{
Ueber einen im Jahre 1625 erschienenen Cometen.
}

Ich verdanke die Kenntnifs dieses Cometen der Histo ixe de l'Astr. moderne von Delambre. In einem Auszuge, den Delambre aus Kepler's Ephemeriden giebt, kommt unter andern Tom. I. p.611. folgendes vor: „Ces Éphémérides ayant éié publiées après coup, c'est à dire 1630 (der ganze zweyte Theil nämlich, der die Ephemeriden von 1621-1628 enthält) Kepler a pu y joindre les observations des phénomènes, qu'elles étaient destinécs à annoncer. $11 \mathrm{y}$ joint encore les obscrvations métcorologiques: enfin, en 1525 il parle de la Cométe observéc en Janvier."
Dafs 1525 ein Druckfehler statt 1625 sey, war zu vermuthen. Aber bisher wufste man von keiner im Jalur 1625 oder auch 1525 statt gefundenen Cometen-Erscheinung, und es schien fast unglaublich, dafs ein von Kepler angefiihrler Comet so ganz unbekannt geblieben seyn sollle. Mir war deswegen, ich gestehe es, irgend eine Irrung bey Delambre wahrscheinlich, und um so wahrscheinlicher, da Scheilel und Kästner in ihren Anszïgen aus denselben Ephemeriden dieses Cometen niclu etwütınen. Ich hat also Herrn Prof. Haraing, die Siclle 
selbst auf der Götlingischen Bibliothec in Keplers Ephemeriden nachzusehen. Mit seiner gewöhnlichen Gefälligkeit hatte der Herr Professor die Güte, mir sogleich eine Abschrift davon zu sehicken, die ich hier folgen lasse.

Am Ende der Epluemeride für 1625 steht nämlich: "Mense Januario Cometa in Ausiria passim animadversus virsus Mcridiem. Ex doctis solum novi Schickardum, Professorem Tübingensem, qui observaverit die 26. Jan. Vesperi, versus occasum, crine longo ab occasu in ortum paulo sursum proreclo. Videtur celeri retrograilo molu Suli obviasse in Capric. signum exitiale inter catera Circulo Saxonico et Austriae Supranisanae. Dicbus 11.12. Februarii Schickardus candam cometican vidit, pridie lsrevem, inter flexus Eridani versus leporem, velut ab 8 Tauri in 5 Gemin. lat. circa $33^{\circ}$ Austr., sed in fine caudae circa 43: postridie longam, australioremque, proxime supra fluxum Eridani a flexu sub ventre Ceti, sub totum leporem, ab initio Tauri in 26 Gemin. versus tergum Sirii, lat. illic 32, hic 49: longitudo ad minimum $45^{\circ}$ in circulo magno. Capilis locum nubila horizontalia texere. Ergo fuit retrogradus, Soli obvians, quia sequentibus diebus non amplius visus."

Also ist wirklich ein Comet von betrüchtlicher Gröfse in Januar und Feluruar 1625 siclitbar gewesen, von dem alle unsere Cometographen bisher nichts wufsten. Obgleich sich aus dieser Nachricht Keplers nur sehr wenig ïber die wahre Bahn des Comclen errathen lifst, so kam sie doch sehr wichtig werden, wenn der Comet unsern Nachkommen einst unler günstigen Umständen wieder erscheincn wird. So viel lüfst sich schliefsen, dafs der Comet seiner wahren Bervegung nach rechiläufig war, und zwischen Erde und Sonne durchlief. Sein Perihcl halte er am $11^{\text {ten }}$ Februar noch nicht erreicht, war ilum aber nahe. Er kam vom niedersteigenten Knolen, und scine heliocentrische südliche Breite nuhm noch bis zum 12ten Febr. zu.
Die Neigung war beträchtlich. Ich muls indessen be. merken, dafs die nach Länge und Breile angegebenen I,agen des Schweifs am $11^{\text {ten }}$ und $12^{\text {ten }}$ Februas, so wie sie angegeben sind, nicht wohl statt finden konnten, und hierinn Fehler des Beobachlers oder des Referenten zu veruuthen sind.

Höchst sonderbar ist es, dafs alle unsere so fleifsigen Sammler der Cometen-Erscheinungen, ein Ricciolus, $\mathrm{Lu}_{\text {- }}$ binietzki, Hevel, Struyck, Pingré von diesen Coluelen nichts wissen. Struyck und Pingré sind in so fern zu entschuldigen, als sie nicht woll glauben konnten, ihre Vorgänger wïrden einen Cometen in Keplers Ephemeriden übersehen haben, und also in diesen nichts suchten. Aber dafs die drey erstgenannien, und so viele andere Schriftstcller des 17ten Jahrhunderts, die gelegentlich in ihren Schriften über einen einzelnen Coucten die rorher. gegangenen Cometen - Erschcinungen aufzühlen, des Cometen von 1625 gar nicht erwähnen, beweist wohl, dafs der zweyle Theil von Keplers Ephemeriden, als ein alter Calender, von seinen Zeitgenussen, und ihren nächsten Nachkommen fast gar nicht gelesen, nicht einmal durchblätlert wurde.

Es käme nun darauf an, ob sich irgendwo noch etwas über diesen Cometen auffinden licfse. Unter Schickards Beubach!ungen, die Lucius Baretus (Albertus Curtius) seiner Historia coelestis beygefügt hat, liommt nichts davon vor. Auch habe ich in mehreren historischen Schriftstellern aus dem 30 jährigen Kriege, die bey den damaligen so bedrängten, und noch so abergläubischen Zeiten jede angtblich vorgefallene Wunder-Erscheinung am Himmel und auf der Erde so sorgfälig anzufiihren pflegen, vergeblich gesucht: Sollte noch ein Astronom, oder anderer Gelehrter üher diesen Cometen elwas wissen, oder finden, so würde ich sehr bitten, es in diesen astronomischen Nachrichten bekannt zu machen.

Schreiben des Herrn Justizraths Matthiessen an den Herausgeber. Altona 1823. April 17.

Sie forderten mich auf, als Sie mir vor einiger Zeit ï̉er meine, zu Allona unter deun 'Titel:

Tafel zur bequemern Berechnung des Logarithmen der Summe oder Differenz, zweyer Gröfsen, wclche sellbst nur durch ihre Logarithmen gegeben sind. gedruckten ' $T$ iffeln manches Verbinilliche sagten, und ich das Lob durch dic Riige mehrerer Unvollkommenheiten meines Verauchs schwächen wollte, Sie forderten mich auf, sage ich, dafs ich thnen gelegentlich schriflich aufgeben möclite, was ich an meinen 'Tafcln zu tadelu fïnde, 